\title{
Influence of prenatal photoperiod on postnatal prolactin secretion in red deer (Cervus elaphus)
}

\author{
C. L. Adam, C. E. Kyle and P. Young \\ Rowett Research Institute, Bucksburn, Aberdeen AB2 9SB, UK
}

\begin{abstract}
Summary. Plasma prolactin concentrations were higher $(P<0.001)$ in newborn red deer calves whose mothers had been maintained for the last 14 weeks of gestation in long days ( $18 \mathrm{~h}$ light) (group L, $n=9$ ) than in those whose mothers had been kept over the same period in short days ( $6 \mathrm{~h}$ light) (group $\mathrm{S}, n=5$ ). After transfer of all hinds and suckled calves on the day of birth to constant intermediate daylength ( $12 \mathrm{~h} \mathrm{light}$ ), prolactin concentrations decreased exponentially $(P<0.001)$ in group $\mathrm{L}$ calves, but not in group $\mathrm{S}$, during the first 21 days. Thereafter, prolactin fell to a nadir in group $\mathrm{L}$ calves and rose to peak values in group $S$ calves at $8-12$ weeks post partum $(P=0.003)$, before converging again by 14 weeks. The pattern of prolactin secretion over the first 14 weeks of life was therefore significantly affected by prenatal photoperiod.

Plasma prolactin concentrations in the adult hinds were higher $(P<0.001)$ in group L than group S at 4-10 weeks before parturition; they were similarly high around parturition and fell thereafter to baseline values after 7 weeks.

These results provide evidence that deer fetuses respond to photoperiodic information, thereby acquiring a photoperiodic history in utero that influences postnatal responses to photoperiod.
\end{abstract}

Keywords: prolactin; gestation; photoperiod; deer

\section{Introduction}

Prolactin secretion is highly responsive to changes in photoperiod in adult red deer and sheep (Brown et al., 1979), being high in long days and low in short days. These changes are mediated by the pattern of pineal melatonin secretion (Brown \& Forbes, 1980; Kennaway et al., 1983) and there is now evidence that the ovine fetus is sensitive to circulating maternal melatonin. Melatonin readily crosses the ovine placenta, producing a diurnal rhythm in melatonin concentrations in fetal plasma (Yellon \& Longo, 1987; Zemdegs et al., 1988) which is abolished by maternal pinealectomy (McMillen \& Nowak, 1989). Prolactin does not cross the ovine placenta (Thomas et al., 1975) but alterations in the maternal photoperiod in late gestation induce changes in plasma prolactin concentrations in fetal (Basset et al., 1989) and neonatal lambs (Ebling et al., 1989). This suggests that the fetus can respond to the maternal melatonin signal; and putative melatonin receptors have been identified in the brain and pituitary of fetal lambs (Helliwell \& Williams, 1990). More recently, similar putative melatonin receptor sites have been identified in fetal and newborn red deer (Helliwell et al., 1991). It is probable that neonatal deer, like neonatal sheep (Ebling et al., 1988), have a functional pineal melatonin system to transduce ambient photoperiodic cues.

The present trial aimed to investigate, by measuring postnatal prolactin secretion, whether fetal red deer receive photoperiodic information in utero. If so, plasma prolactin concentrations in the neonate might depend on whether their mothers had been maintained in long days ( $18 \mathrm{~h} \mathrm{light:6 \textrm {h }}$ dark) or short days ( $6 \mathrm{~h}$ light: $18 \mathrm{~h}$ dark) during gestation. After transfer on the day of birth of all dams and calves to intermediate daylength ( $12 \mathrm{~h}$ light:12 h dark), subsequent changes in postnatal 
prolactin secretion might then be expected to reflect the maternal pregnancy photoperiod, viz. calves receiving long days in utero might respond to intermediate days as short days (and prolactin secretion would decrease) and those receiving short days in utero might respond to intermediate days as long days (and prolactin secretion would increase).

\section{Materials and Methods}

\section{Animals and treatment}

Pregnant red deer hinds from the Rowett Research Institute herd were individually penned and housed in lightsealed controlled-photoperiod rooms from about 19 weeks of gestation in March 1990. Fluorescent lights, regulated by electric time clocks, provided a daytime light intensity of about $200 \mathrm{~lx}$. Ten hinds (group L) were given long days

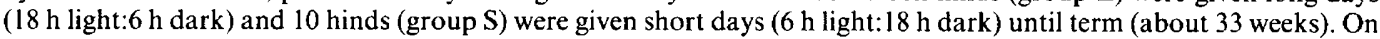
the day of birth, the newborn calves and their dams were transferred to intermediate daylength $(12 \mathrm{~h}$ light:12 h dark) where they were kept until weaning at 14 weeks post partum. All hinds were given a complete diet ( $50 \%$ hay) daily. Calves were weighed weekly from birth.

\section{Blood sampling}

Blood was collected by jugular venepuncture into heparinized vacutainer tubes, $1-2 \mathrm{~h}$ after lights-on, from calves daily for the first 3 weeks of life and then twice a week until weaning, and from hinds twice a week throughout. Plasma was stored at $-20^{\circ} \mathrm{C}$ until required for assay.

\section{Prolactin assay}

Concentrations of plasma prolactin were determined by a radioimmunoassay based on that of Chesworth (1977), as described by Adam et al. (1987, 1989a). Inter- and intra-assay coefficients of variation were 12 and 4\%, respectively, determined at concentrations of 73.8 and $75.4 \mathrm{ng} \mathrm{ml}^{-1}$, and sensitivity averaged $4 \mathrm{ng} \mathrm{ml}^{-1}$.

\section{Statistical analysis}

Mean birth and weaning weights were compared by Student's $t$ test. Prolactin data were subjected to analyses, using GENSTAT 5, aimed at minimizing the effects of large variabilities. Birth to 21-day values for calves were averaged over 3 days and compared by $t$ test. Exponential curves were fitted to the daily mean prolactin values, using a standard least-squares technique, to describe the temporal changes in prolactin over the 21 days. Values for calves from birth to 14 weeks were averaged over defined periods and analysis of variance was applied using a split-plot arrangement to allow for repeated measurements. Prolactin values for hinds were also averaged over defined periods and the groups compared by $t$ test with adjusted degrees of freedom to allow for differences in variability between the groups.

\section{Results}

All surviving calves born to group $\mathrm{L}$ hinds were male $(n=9)$, so that data from only the male calves born to group $\mathrm{S}$ hinds $(n=5)$ and data only from corresponding dams (L, $n=7 ; \mathrm{S}, n=5)$ are presented. All calves were singletons; (data from two group L dams are excluded since blood samples were not taken after parturition).

Mean $( \pm$ SEM) birth weights $(7.5 \pm 0.46$ and $7.4 \pm 0.21 \mathrm{~kg})$ and 14-week weaning weights $(36.9 \pm 0.77$ and $37.5 \pm 1.21 \mathrm{~kg}$ ) did not differ significantly between group $\mathrm{L}$ and group $\mathrm{S}$ calves, respectively.

On day 2 after birth (mean of days 1-3) group $L$ calves had significantly higher concentrations of plasma prolactin $(P<0.001)$ than group $\mathrm{S}$ calves (Fig. 1a). Thereafter, group $\mathrm{L}$ values declined exponentially $(P<0.001)$ to the same as those in group $S$, whereas group $S$ values did not alter significantly over this period.

Over the longer 14-week postnatal period (Fig. 1b) prolactin concentrations rose to peak values in group $\mathrm{S}$ calves, and continued to fall to a nadir in group L calves, before converging again by 14 weeks. Analysis of data averaged over the periods $2-4 \cdot 5$ and 5-7.5 weeks revealed no significant difference between the groups (Table 1) although a slight divergence was apparent in the 
(a)

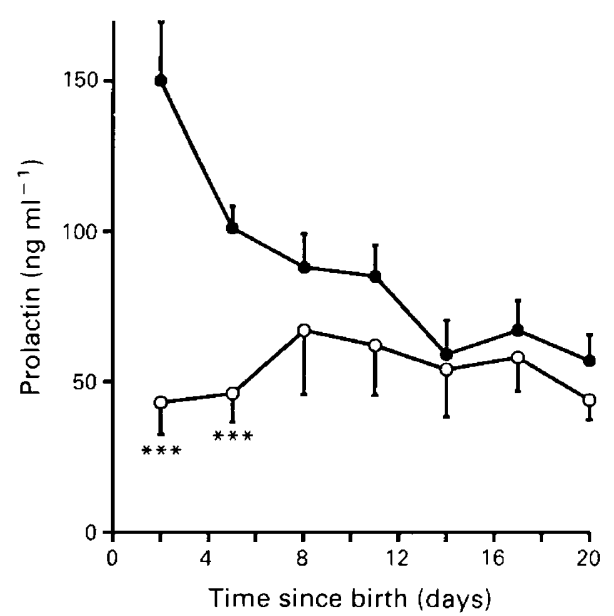

(b)

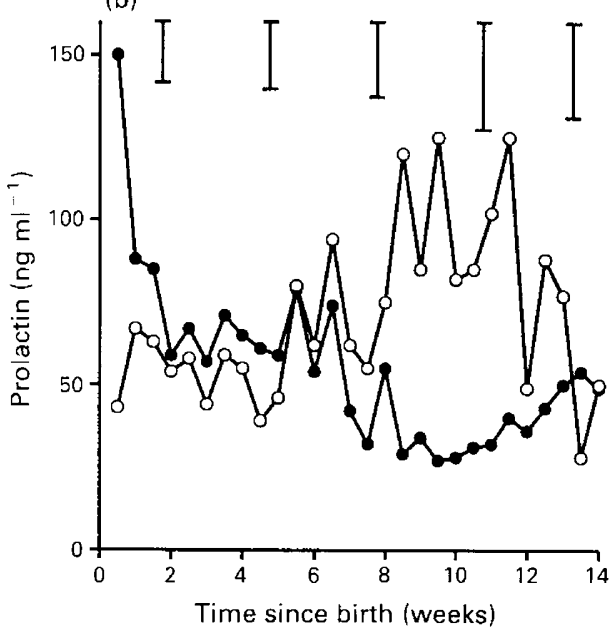

Fig. 1. Concentrations of plasma prolactin in suckled red deer calves kept in intermediate daylength ( $12 \mathrm{~h}$ light: $12 \mathrm{~h}$ dark) whose mothers had been kept for the last 14 weeks of gestation in long days $(\bullet, n=9)$ or short days $(O, n=5)$. (a) 3-day means ( \pm SEM) from birth to 21 days $\left({ }^{* * *} P<0.001\right)$ and (b) twice-a-week mean values from birth to 14 weeks (SED values given for 3 week periods).

latter period. However, over $8-10$ and $10 \cdot 5-12$ weeks, group $\mathrm{S}$ prolactin values were significantly $(P=0.003)$ higher than those for group $\mathrm{L}$ in both periods. By 14 weeks there was no significant difference between the groups.

Table 1. Mean concentrations of plasma prolactin $\left(\mathrm{ng} \mathrm{ml}^{-1}\right)$ 2-12 weeks after birth in red deer calves kept in intermediate daylength $(12 \mathrm{~h}$ light: $12 \mathrm{~h}$ dark) whose mothers had been kept in long days (group $\mathrm{L}, n=9$ ) or short days (group $\mathrm{S}, n=5$ )

\begin{tabular}{lcccc}
\hline & \multicolumn{5}{c}{ Period (weeks) } \\
\cline { 2 - 5 } Group & $2-4 \cdot 5$ & $5-7 \cdot 5$ & $8-10$ & $10 \cdot 5 \cdot 12$ \\
\hline L & $55 \cdot 7$ & $56 \cdot 6$ & $34 \cdot 4^{\mathrm{a}}$ & $29 \cdot 5^{\mathrm{a}}$ \\
S & $52 \cdot 4$ & $68 \cdot 1$ & $97 \cdot 2^{\mathrm{b}}$ & $90 \cdot 4^{\mathrm{b}}$ \\
\cline { 2 - 5 } & \multicolumn{2}{c}{$6 \cdot 16$} & \multicolumn{2}{c}{$9 \cdot 49$} \\
\hline
\end{tabular}

${ }^{a}$ versus ${ }^{b}, P=0.003$.

Analysis of the mean prolactin concentrations for the hinds (Fig. 2) revealed that prolactin values were significantly higher $(P<0.001)$ for group $L$ than for group S $10-4$ weeks before parturition (i.e. 4-10 weeks following start of daylength treatments) and 2-5 weeks after parturition (Table 2). Both groups had high prolactin concentrations around parturition and concentrations fell thereafter to level out after about 7 weeks.

\section{Discussion}

In this study, postnatal concentrations of plasma prolactin in red deer calves were influenced by the photoperiod experienced by the dam in late gestation. Neonatal plasma prolactin concentrations 


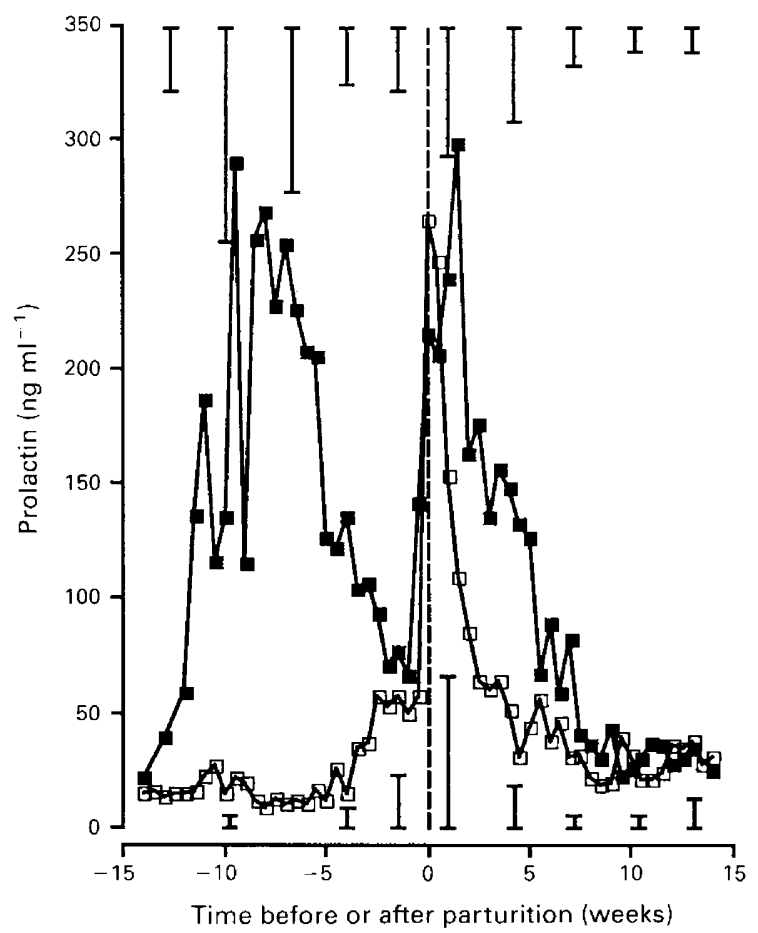

Fig. 2. Concentrations of plasma prolactin (mean \pm SEM) in red deer hinds kept in long days (group L, $\mathbf{\square}, n=7$ ) or short days (group $\mathrm{S}, \square, n=5$ ) for the last 14 weeks of gestation and

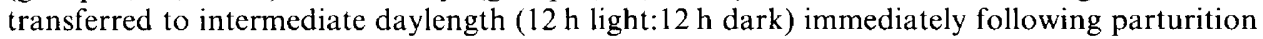
(week 0); SEM values averaged over 3 weeks are given for group L (top of figure) and group S (bottom of figure).

Table 2. Mean ( \pm SEM) concentrations of plasma prolactin (ng ml ${ }^{-1}$ ) 4-10 weeks before and 2-5 weeks after parturition in red deer hinds kept in long (group $\mathrm{L}, n=7$ ) or short (group $\mathrm{S}, n=5$ ) days for the last 14 weeks of gestation and in intermediate daylength ( $12 \mathrm{~h}$ light: $12 \mathrm{~h}$ dark) after calving

\begin{tabular}{lrcr}
\hline & \multicolumn{3}{c}{ Period (weeks) } \\
Group & $10-7 \cdot 5$ & $7-4$ & After parturition \\
& \multicolumn{2}{c}{ Before parturition } & $2-5$ \\
\hline $\mathrm{S}$ & $215 \cdot 4 \pm 64 \cdot 0^{\mathrm{a}}$ & $209 \cdot 6 \pm 46 \cdot 2^{\mathrm{a}}$ & $152 \cdot 5 \pm 45 \cdot 8^{\mathrm{c}}$ \\
& $16 \cdot 0 \pm 4 \cdot 6^{\mathrm{b}}$ & $15 \cdot 2 \pm 4 \cdot 1^{\mathrm{b}}$ & $57 \cdot 1 \pm 14 \cdot 7^{\mathrm{d}}$ \\
\hline
\end{tabular}

${ }^{\mathrm{a}}$ versus ${ }^{\mathrm{b}} ;{ }^{\mathrm{c}}$ versus ${ }^{\mathrm{d}}, P<0.001$.

(Fig. la) were high in calves born to dams maintained in long days, but low in calves born to dams maintained in short days, reflecting the pattern of secretion in utero. These results, together with the recent identification of melatonin receptors in the brain and pituitary of deer fetuses (Helliwell et al., 1991), indicate strongly that deer fetuses receive and respond to photoperiodic information from their dam. After transfer at birth to intermediate daylength, and in the absence of any further photoperiodic change, the pattern of postnatal prolactin secretion over the first 14 weeks of life 
was profoundly influenced by prenatal photoperiod. Since prolactin apparently does not transfer across the ovine placenta (Thomas et al., 1975), which is similar in type to the cervine placenta (see Steven, 1975), nor through ewe's milk (Ebling et al., 1988), and since the pattern of changing concentrations differed so markedly between dams and calves in the present trial, it was concluded that plasma concentrations truly reflected prolactin secretion, and hence response to photoperiod, in suckled calves from birth.

The initial postnatal decrease in prolactin concentrations shown by group $L$ calves (Fig. 1a) indicated that the neonate was responding as predicted to the relative photoperiodic change to intermediate daylength, like similarly-treated lambs (Ebling et al., 1989). Conversely, group $\mathrm{S}$ calves showed no significant neonatal changes in prolactin secretion, suggesting that they were initially still perceiving intermediate days as short days; however, after about 5 weeks (Fig. $1 \mathrm{~b}$ ) their prolactin concentrations rose, suggesting that they were reading intermediate days as long days, as predicted, but the response took longer to develop. Furthermore, over the period from birth to 14 weeks, the inverse patterns of prolactin secretion shown by the two groups (Fig. 1b), in the absence of any further change in photoperiod, provide clear evidence for a longer term influence of prenatal photoperiod. The observed changes after the predicted responses may reflect the development of refractoriness to the ambient photoperiod, or the differential programming in utero of an endogenous rhythm of prolactin secretion with an apparent periodicity (from peak to trough) of about $9-10$ weeks.

Prolactin secretion responded initially as predicted in the pregnant hinds, rising in long days and remaining low in short days. However, short days failed to prevent the characteristic periparturient prolactin surge, as reported previously for melatonin-treated hinds (Adam et al., 1989a); it was considered unlikely that this rise was due to developing refractoriness since hinds given melatonin (mimicking short days) over prolonged periods do not become refractory (Adam et al., $1989 \mathrm{~b}$ ). There was perhaps evidence of some refractoriness to long days from the spontaneous decline in prolactin concentrations after about 8 weeks, but again this failed to prevent the peri-parturient rise.

After parturition, prolactin responses to the photoperiodic change shown by the adult hinds (Fig. 2) were markedly different from those of their calves. There was no evidence that the hind interpreted intermediate daylength differently according to her preceding photoperiod. Although the response to photoperiod around parturition was probably masked by responses to physiological cues, both groups showed a steady decline in prolactin concentrations from the peri-parturient peak, as witnessed in hinds calving and lactating in short days (Adam et al., unpublished data) or while on daily melatonin treatment (Adam et al., 1989a). The fact that group L values remained significantly higher than group S values $2-5$ weeks postnatally was thought to reflect a displacement of the decay curve for prolactin from a later and slightly higher peak (Fig. 2). There was no significant difference between the groups from 5 weeks onwards and 'baseline' levels were maintained from about 7 weeks. Interestingly, although both groups were apparently reading intermediate days as short days, the 'baseline' prolactin concentration achieved postnatally in intermediate daylength was actually higher than the 'baseline' concentration shown in short days prenatally (Fig. 2). In contrast to their calves, the hinds showed no further changes in prolactin secretion, indicating no evidence for developing refractoriness or for an endogenous rhythm with a periodicity of less than 14 weeks. Clearly there was a difference between the mature and immature response to the photoperiodic change from long or short days into intermediate daylength. There was no evidence for a differential effect of the photoperiodic treatments on birth weight or suckled calf live-weight gain (indicative of hind milk yield) to 14 weeks.

It is concluded that deer fetuses can receive and respond to photoperiodic information, thereby acquiring a photoperiodic history in utero that can influence postnatal responses to photoperiod. The significance of these findings in relation to reproductive development and the timing of puberty is currently under investigation. 
We thank A. Thomson and D. Wilkie for their excellent daily care of the animals, and I. Nevison and M. Franklin of Scottish Agricultural Statistics Service for assistance with data analysis and presentation.

\section{References}

Adam, C.L., Atkinson, T. \& Moir, C.E. (1987) Melatonin lowers plasma prolactin levels in female red deer (Cervus elaphus). Journal of Pineal Research 4, 13-20.

Adam, C.L., Moir, C.E. \& Shiach, P. (1989a) Plasma prolactin concentrations in barren, pregnant and lactating red deer (Cervus elaphus) given melatonin to advance the next breeding season. Animal Reproduction Science 18, 77-86.

Adam, C.L., Moir, C.E. \& Shiach, P. (1989b) Melatonin can induce year-round ovarian cyclicity in red deer (Cervus elaphus). Journal of Reproduction and Fertility 87, 401-408.

Basset, J.M., Curtis, N., Hanson, C. \& Weeding, C.M. (1989) Effects of altered photoperiod or maternal melatonin administration on plasma prolactin concentrations in fetal lambs. Journal of Endocrinology 122, 633.643 .

Brown, W.B. \& Forbes, J.M. (1980) Diurnal variations of plasma prolactin in growing sheep under two lighting regimes and the effect of pinealectomy. Journal of Endocrinology 84, 91-99.

Brown, W.B., Forbes, J.M., Goodall, E.D., Kay, R.N.B. \& Simpson, A.M. (1979) Effects of photoperiod on food intake, sexual condition and hormone concentrations in stags and rams. Journal of Physiology 296, $58-59 \mathrm{P}$.

Chesworth, J.M. (1977) Radioimmunoassay of ovine LH and ovine prolactin using polymerized second antisera. Analytical Biochemistry 80, 31-40.

Ebling, F.J.P., Claypool, L.E. \& Foster, D.L. (1988) Neuroendocrine responsiveness to light during the neonatal period in the sheep. Journal of Endocrinology 119, 211-218.

Ebling, F.J.P., Wood, R.J., Suttie, J.M., Adel, J.E. \& Foster, D.L. (1989) Prenatal photoperiod influences neonatal prolactin secretion in the sheep. Endocrinology 125, 384-391.
Helliwell, R.J.A. \& Williams, L.M. (1990) Ontogeny of central melatonin receptors in the sheep. Neuroendocrinology 52, Supplement 1, P2.116.

Helliwell, R.J.A., Adam, C.L., Hannah, L.T., Kyle, C.E. \& Williams, L.M. (1991) The distribution of central $2-\left[{ }^{125} \mathrm{I}\right]$-iodomejatonin binding sites in the adult and fetal red deer (Cervus elaphus). Journal of Reproduction and Fertility Abstract Series No. 8, Abstract No. 117.

Kennaway, D.J., Sanford, L.M., Godfrey, B. \& Friesen, H.G. (1983) Patterns of progesterone, melatonin and prolactin secretion in ewes maintained in four different photoperiods. Journal of Endocrinology 97, 229-242.

McMillen, I.C. \& Nowak, R. (1989) Maternal pinealectomy abolishes the diurnal rhythm in plasma melatonin concentration in the fetal sheep and pregnant ewe during late gestation. Journal of Endocrinology 120, $459-464$.

Steven, D.H. (1975) Comparative Placentation. Academic Press, London, New York and San Francisco.

Thomas, A.L., Jack, P.M.B., Manns, J.G. \& Nathanielsz, P.W. (1975) Effect of synthetic thyrotropin releasing hormone on thyrotropin and prolactin concentrations in the peripheral plasma of the pregnant ewe, lamb fetus and neonatal lamb. Biology of the Neonate 26, $109-114$

Yellon, S.M. \& Longo, L.D. (1987) Melatonin rhythms in fetal and maternal circulation during pregnancy in sheep, American Journal of Physiology 252, E799-802.

Zemdegs, I.Z., McMillen, I.C., Walker, D.W., Thorburn, G.D. \& Nowak, R. (1988) Diurnal rhythms in plasma melatonin concentrations in the fetal sheep and pregnant ewe during late gestation. Endocrinology 123, 284289 .

Received 2 September 1991 